\title{
Atomic Layer Deposition Grown Zinc-Oxide based MIS- Type Schottky Barrier Diode
}

\author{
N. Kaymak ${ }^{1}$, E. Efil ${ }^{2}$, E. Seven ${ }^{3}$, A. Tataroğlu ${ }^{2}$, S. Bilge Ocak ${ }^{1 *}$, and E. Öz Orhan ${ }^{2}$ \\ ${ }^{1}$ Gazi University, Graduate School of Natural and Applied Sciences, Department of Advanced \\ Technologies, 06500 Ankara, Turkey \\ ${ }^{2}$ Gazi University, Faculty of Science, Department of Physics, 06500 Ankara, Turkey \\ ${ }^{3}$ Atatürk University, Graduate School of Natural and Applied Sciences, Department of Nanoscience \\ and Nanoengineering 25100 Erzurum, Turkey
}

*Corresponding author: sbocak@gazi.edu.tr, semabilge72@gmail.com

\begin{abstract}
We report on the fabrication and electrical characteristics of zinc-oxide ( $\mathrm{ZnO})$ based metal-insulator-semiconductor (MIS) type Schottky barrier diodes (SBHs). ZnO thin layer on the p-type silicon substrate was fabricated by atomic layer deposition (ALD). The structure and surface properties of the thin film were characterized by X-ray diffraction (XRD), atomic force microscope (AFM) and secondary ion mass spectrometer (SIMS). The current-voltage (I-V) characteristics of $\mathrm{Al} / A L D$-grown $\mathrm{ZnO} / \mathrm{p}$-Si diodes were measured under dark at room temperature. The electrical parameters such as ideality factor (n), series resistance $\left(\mathrm{R}_{\mathrm{s}}\right)$ and barrier height $\left(\phi_{b}\right)$ of the diodes were analyzed using standard thermionic emission (TE) theory, Norde and Cheung method. The barrier height value obtained from I-V and Cheung method was found to be $0.73 \mathrm{eV}$ and $0.76 \mathrm{eV}$, respectively. The interface state density (Dit) of the diodes was determined from the I-V characteristics. The nonideal behavior of measured parameters suggested the presence of interface states. The obtained results showed that the prepared diode can be used for NIR Schottky photodetector applications.
\end{abstract}

Key words: Atomic Layer Deposition, $\mathrm{ZnO}$, ideality factor, series resistance, Schottky photodetector

\section{Introduction}

Zinc oxide $(\mathrm{ZnO})$, which has excellent electronic and optoelectronic properties such as high dielectric constant, high thermal stability, large saturation velocity, wide band gap $(3.37 \mathrm{eV})$ and high exciton binding energy $(60 \mathrm{MeV})$, is one of the most used materials. Zinc oxide is an n-type semiconductor and a transparent conductive oxide [1]. Because of these excellent properties, Zinc oxide is used applications such as solar cells, biosensors, gas sensors, optoelectronic devices, transducers [2-5], liquid crystals display, light emitting diodes [6], visible light and UV photo-detectors [7, 8]. ZnO layers have been grown by using different deposition techniques such as sol-gel, spin coating method [9], reactive evaporation [10], chemical vapor deposition (CVD) [11], magnetron sputtering [12], and atomic layer deposition (ALD) [13]. In the recent years, there has remarkable interest to deposit $\mathrm{ZnO}$ thin 
films using atomic layer deposition. ALD is the special type of chemical vapor deposition technique which is based on sequential self-limiting surface reactions. Compared to other CVD technique, precursors are introduced to the surface at separate cycles. During each cycle, saturation of the precursor on the surface occurs and this results in a self-limiting growth [14]. This technique can produce suitable surfaces with high precision at the atomic scale and control sensitive film thickness. For this reason, it is a production technique that provides great advantages in thin film technology [15]. The ALD method allows high-quality thin films to be produced at low temperatures because the precursors of the gas phase can be held on the surface without going out to very high temperatures [16]. In ALD technique, the reactions reach saturation after forming a single atomic layer. This provides accurate, precise and easy thickness control and homogeneous coating. The film thickness depends only on the number of reaction cycles. In this way, it is possible to conformal coat even the most challenging geometric shaped surfaces. ALD is a perfect method for depositing thin films with 3D structures. The ALD technique has high performance in the 3D aspect in high/ aspect ratio [17]. ALD is very compatible substrate surface. ALD has many features such as reproducibility, good film density, low-temperature growth, uses very reactive precursors [1820]. ALD-grown $\mathrm{ZnO}$ is shown a great potential for various nano-electronic device applications such as dynamic random access memory (DRAM), high-k gate dielectrics for CMOS, multilayer capacitors, organic light emitting diode (OLED layers), optical filters, integrated optics, transparent conductive oxide (TCOS) layer used thin film solar cells and photo-detectors, photonic crystals, atomic force microscope tips, nanotubes, nano-rods and nano-dots [18-22].

In this study, $\mathrm{ZnO}$ layer was deposited on p-type Si by using the ALD technique to prepare high-quality Al/ALD- grown $\mathrm{ZnO} / \mathrm{p}-\mathrm{Si}$ Schottky diodes. The MIS type diode was analyzed by using XRD, AFM, and SIMS. The current-voltage (I-V) characteristics were measured under dark and at room temperature. The ideality factor $(n)$, series resistance $\left(R_{S}\right)$, barrier height $\left(\phi_{b}\right)$ of the prepared diodes were analyzed by using standard thermionic emission (TE) theory, Norde's function and Cheung methods.

\section{Experimental}

In this work, we used p-type Si (100) wafer which had $380 \mu \mathrm{m}$ thickness and 1-10 $\Omega \mathrm{cm}$ resistivity as the substrates. Before processing the wafer, Radio Corporation of America (RCA) cleaning procedures were applied for removing organic residues from $p$-type Si wafer [23]. In order to form an ohmic contact, $\mathrm{Al}$ (99.999\%) metal was deposited on the unpolished back surface of the wafer with a thickness of $124 \mathrm{~nm}$ by using sputtering systems at $500^{\circ} \mathrm{C}$ under $4.7 \times 10^{-6}$ Torr pressure condition. After the wafer was annealed at $500^{\circ} \mathrm{C}$ for $10 \mathrm{~min}$ to dope aluminum into the back surface of the wafer, again, the back surface of the wafer was coated by $\mathrm{Al}$ with a thickness of $124 \mathrm{~nm}$ at room temperature for completing ohmic contact. $\mathrm{ZnO}$ was deposited on the polished p-type Si (100) wafer by using ALD (Okyay Nanotech) at a low substrate temperature of $170{ }^{\circ} \mathrm{C}$. $\mathrm{ZnO}$ deposition was performed for 125 cycles to achieve a layer thickness of $16 \mathrm{~nm}$ at a growth rate of $1.29 \AA$ /cycle. Diethylzinc $\left(\mathrm{Zn}_{(}\left(\mathrm{C}_{2} \mathrm{H}_{5}\right)_{2}\right.$ (DEZ)) and $\mathrm{H}_{2} \mathrm{O}$ were used as precursor materials of $\mathrm{ZnO}$. Nitrogen (\%99.999) was used as a 
carrier and cleaning gas with a flow rate of $7 \mathrm{sscm}$ to separate precursor cycles. System pressure is $2.72 \times 10^{-1}$ Torr, circle inner temperature is $170{ }^{\circ} \mathrm{C}$ and precursive temperatures is $150{ }^{\circ} \mathrm{C}$. One $\mathrm{ZnO}$ ALD cycle consists of $100 \mathrm{~ms}$ DEZ pulse, $20 \mathrm{~s} \mathrm{~N}_{2}$ purge, $15 \mathrm{~ms} \mathrm{H}_{2} \mathrm{O}$ pulse and $10 \mathrm{~s} \mathrm{~N}_{2}$ purge, respectively. Later, the high purity ( 99.999\%) of $128 \mathrm{~nm}$ thick Al dots by using the mask with the shape of circular dots of $1.5 \mathrm{~mm}$ in diameter to rectify contacts were deposited the $\mathrm{ZnO}$ layer at room temperature by using the sputtering technique at $7.06 \times 10^{-6}$ Torr. The schematic representation of the obtained $\mathrm{Al} / A L D$-grown $\mathrm{ZnO} / \mathrm{p}-\mathrm{Si}$ Schottky barrier diode is seen in Fig.1.

\section{Results and Discussion}

\subsection{Surface morphology and depth profile}

The surface structure of the $\mathrm{ZnO}$ films was clarified by using a high performance atomic force microscope (AFM) (Nano Magnetics Instruments Ltd., Oxford, UK) by dynamic mode scanning at room temperature (RT). The scanning speed was set at $1 \mu \mathrm{m} / \mathrm{s}$, and the area of $3 \times$ $3 \mu \mathrm{m}^{2}$ was scanned. Fig. 2 shows AFM images and the surface morphology of the grown $\mathrm{ZnO}$ films on the p-type Si substrate. It can be easily seen from the three-dimensional (3D) and two-dimensional (2D) AFM images with $3 \times 3 \mu^{2}$ scan area of the sample shown in Fig. 2 that its surface is quite homogeneous at the nano-scale with a roughness of $3.17 \mathrm{~nm}$ and no particular defects can be observed.

The depth profile of the $\mathrm{ZnO}$ film on the $\mathrm{Si}$ substrate was carried out by using Hiden Analytical SIMS Workstation with Cs+ ion for sputtering having $5 \mathrm{keV}$ energy and $30 \mathrm{nA}$ beam current. To prevent faulty signals, the depth profile was recorded in MCs+ cluster mode, scanning for atomic masses 129, 160 and 197 for OCs, SiCs, and ZnCs, respectively. Secondary Ion Mass Spectrometer (SIMS) measurement was performed under a vacuum of $10^{-8}$ Torr. A stylus type profilometer (Veeco, Dektak 150) was used to measure the depth of the crater which has $100 \mu \mathrm{m}^{2}$ area obtained by the Cs ion gun etching of the sample.

Fig. 3 shows the depth profile of the grown $\mathrm{ZnO}$ film on the p-type Si substrate. It was clearly seen that the distribution of the both $\mathrm{Zn}$ and $\mathrm{O}$ was uniform throughout the depth of the achieved film. In addition, the thickness of the $\mathrm{ZnO}$ layer was about $15-20 \mathrm{~nm}$ which is the same target thickness of the growth procedure. The constant stoichiometry of the film was observed from SIMS results with the help of the signals of the MCs+ detected sensitively. 


\subsection{Electrical properties of Al/ ALD-grown ZnO /p-Si Schottky barrier}

Firstly, the electrical characteristics of $\mathrm{Al} / \mathrm{ALD}$-grown $\mathrm{ZnO} / \mathrm{p}-\mathrm{Si}$ Schottky barrier diodes have been examined by using the standard thermionic emission (TE) theory. According to the TE theory, relation between forward bias voltage $(V>3 k T / q)$ and current through a Schottky diode is given [24].

$$
\begin{array}{r}
I=I_{0} \exp \left(\frac{q V}{n k T}\right)\left[1-\exp \left(-\frac{q V}{k T}\right)\right] \\
I_{0}=A A^{*} T^{2} \exp \left(-\frac{q \phi_{b}}{k T}\right)
\end{array}
$$

where $I_{0}$ is saturation current which obtained from the straight line intercept of the $\ln I-\mathrm{V}$ plot at $\mathrm{V}=0 . A^{*}$ is determined as the Richardson constant $\left(32 \mathrm{~A} / \mathrm{cm}^{2} \mathrm{~K}^{2}\right.$ for $p$-type $\mathrm{Si}$ ). $\mathrm{q}, \mathrm{k}$, and $\mathrm{T}$ are the electron charge, the Boltzmann's constant, the temperature in Kelvin, respectively. A, $\phi_{b}, \mathrm{~V}$ are described as the diode area, the effective barrier height, the applied voltage, respectively.

The values of ideality factor $(n)$ were obtained from the slope of the semi-logarithmic I$\mathrm{V}$ plots for the linear region by using Eq.(3) [24].

$$
n=\frac{q}{k T} \frac{d V}{d(\ln I)}
$$

$\phi_{b}$ can be derived from Eq. (4) as are given by

$$
\phi_{b}=\frac{k T}{q} \ln \left(\frac{A A^{*} T^{2}}{I_{0}}\right)
$$

Fig. 4 shows that the measured I-V and lnI-V characteristics of the three diodes (D1, D2, and D3) on $\mathrm{Al} / \mathrm{ALD}$-grown $\mathrm{ZnO} / \mathrm{p}-\mathrm{Si}$ Schottky diodes at room temperature, respectively. The values of $\phi_{b}$ were calculated from the intercepts of the forward bias $\ln I-\mathrm{V}$ plot at room temperature.

It is thus easy to understand in Fig. 4, the I-V characteristics of $\mathrm{Al} / A L D$-grown $\mathrm{ZnO} / \mathrm{p}-\mathrm{Si}$ structure show perfect rectifying behavior although low leakage. The reason of rising to the curvature at high currents in the semi-logarithmic $\ln (\mathrm{I})-\mathrm{V}$ characteristics is that the current curve in the forward bias region becomes dominated by series resistance from contact wires 
or bulk resistance of MIS structures. Therefore, the values of series resistance were calculated by using Norde's and Cheung methods.

In this study, we used the modified Norde's function method suggested by Norde to determine the value of series resistance and barrier height. According to this method, the applied voltage is greater than 3kT/q like TE theory. In case of ideal Schottky barrier diode with $n=1$, Norde's function $F(V)$ can be described by the following equation [25].

$$
F(V, I)=\frac{V}{2}-\frac{k T}{q} \ln \left(\frac{I(V)}{A A^{*} T^{2}}\right)
$$

$\mathrm{I}(\mathrm{V})$ is current taken from I-V curve. The minimum value $F\left(V_{0}\right)$ is obtained from $F(V)$ vs $V$ plot. The barrier height of Schottky diode is defined as

$$
\phi_{b}=F\left(\mathrm{Vo}_{0}\right)+\frac{V_{\mathrm{o}}}{2}-\frac{k T}{q}
$$

where $\mathrm{V}_{0}$ is corresponding applied voltage. $\mathrm{F}(\mathrm{V})-\mathrm{V}$ plots of the $\mathrm{Al} / A L D$-grown $\mathrm{ZnO} / \mathrm{p}-\mathrm{Si}$ structure is shown in Fig.5. The values of series resistance $\left(R_{s}\right)$ can be calculated by using the formula.

$$
\operatorname{Rs}=\frac{k T}{q I}
$$

By using Eq (6) and (7), the obtained series resistance and barrier height values of D1, D2 and D3 diodes were given in Table 1.

Rs is significant in the linear region that is the downward curvature of the forward bias I-V characteristics, however, the other two parameters that are $\mathrm{n}$ and $\phi_{b}$, are significant in both the non-linear and linear regions of I-V characteristics. The values of $\mathrm{n}, \phi_{b}$, and Rs were calculated by using a method that developed by S.K. Cheung and N.W Cheung [26]. According to this method, $n, \phi_{b} . \mathrm{R}_{\mathrm{s}}$ and $\mathrm{H}(\mathrm{I})$ can be written as

$$
\begin{aligned}
& \frac{d V}{d(\ln I)}=n \frac{k T}{q}+I R_{s} \\
& H(I)=V-\frac{n k T}{q} \ln \left(\frac{I}{A A^{*} T^{2}}\right)
\end{aligned}
$$




$$
H(I)=n \phi_{b}+I R_{s}
$$

The barrier height $\left(\phi_{\mathrm{b}}\right)$ was obtained from the linear region in the forward bias $\mathrm{I}-\mathrm{V}$ characteristics. In Fig. 6, experimental dV/dlnI vs I and H(I) vs I plots are presented for typically three diodes on $\mathrm{A} 1 / A L D$-grown $\mathrm{ZnO} / \mathrm{p}$-Si Schottky structure at room temperature, respectively.

The plot of $d V / d(\ln I)$ vs $I$ is linear having the slope of $R_{s}$ and nkT/q y-axis interception point, because of Eq. (8) gives a straight line towards the bottom left curvature region in the forward bias $\mathrm{I}-\mathrm{V}$ characteristics. $\mathrm{R}_{\mathrm{s}}$ value is obtained from the slope of the $\mathrm{dV} / \mathrm{d}(\mathrm{ln} \mathrm{I})$ vs I curve and $\mathrm{n}$ is obtained from the cut-point of the curve. In Eq. (10), $R_{\mathrm{s}}$ from the slope of the $\mathrm{H}(\mathrm{I})$ vs I curve and $\phi_{\mathrm{b}}$ from the cut-off point of the curve are obtained using the $\mathrm{n}$ value found in Eq. (8). As seen in Table 1, $\mathrm{n}, \phi_{\mathrm{b}}$ and $\mathrm{R}_{\mathrm{s}}$ values are calculated for typically D1, D2, and D3 diodes.

For the typically three diodes (D1, D2, and D3) on $\mathrm{Al} / A L D$-grown $\mathrm{ZnO}$ / $\mathrm{p}$-Si structure, the values of $n, \Phi_{b}$ and $R_{s}$ expressing the electrical properties are given in the Table 1 . According to the standard method, the values of $\mathrm{n}$ are in accordance with those of Cheung method. The $\Phi_{\mathrm{b}}$ values for all three methods are in agreement each other. As it is expected, the $R_{s}$ values obtained by using Norde method that is considered to be ideal $(n=1)$, are higher than the obtained values by using both standard and Cheung methods. The values of $\phi_{b}$ obtained from lnI-V plots, Norde's function and Cheung method are different from each other by comparing their results. These differences may be due to the extraction from the different region of the I-V plot. The values of $R_{s}$ calculated from Norde's method is higher than those of calculated another method. While Norde's model is executed for the all forward bias region of I-V plots, Cheung's model is executed for a nonlinear high-voltage region of the forward bias of I-V plots [27].

Downward curvature of the forward bias I-V characteristics may be due to the fact that effect of interface states. The density distribution profile of the interface state $\left(D_{i t}\right)$ in equilibrium with semiconductor can high-performance by using the forward bias I-V curves. In case of the presence of interfacial insulator layer and interface states, the voltage-dependent of the barrier height is determined as

$$
\frac{d \phi_{e}}{d V}=\Gamma=1-\frac{1}{n(V)}
$$


where $\phi_{e}, \Gamma$ are the effective of barrier height, the voltage coefficient of the effective of barrier height, respectively. The voltage-dependent of $\phi_{e}$ is described by

$$
\phi_{e}=\phi_{B}+\left(1-\frac{1}{n(V)}\right) V
$$

According to Card and Rhoderick [28, 29], $\mathrm{D}_{\mathrm{it}}$ versus $\mathrm{E}_{\mathrm{ss}}-\mathrm{E}_{\mathrm{v}}$ for $\mathrm{p}$-type semiconductor barrier diode can be given as

$$
\begin{aligned}
& n(V)_{\text {⿴囗 }}=1+\frac{\delta}{\varepsilon_{i}}\left[\frac{\varepsilon_{s}}{W_{D}}+q D_{i t}(V)\right] \\
& n(V)=\frac{q}{k T}\left(V_{i} \ln \left(\frac{I_{i}}{I_{0}}\right)\right) \\
& D_{i t}=\frac{1}{q}\left[\frac{\varepsilon_{i}}{\delta}(n(V)-1)-\frac{\varepsilon_{i}}{W_{D}}\right]
\end{aligned}
$$

where $\delta=16 \mathrm{~nm}$ is the thickness of the interfacial insulator. $\varepsilon_{\mathrm{s}}=11.8 \varepsilon_{0}$ and $\varepsilon_{\mathrm{i}}=8.65 \varepsilon_{0}$ are the permittivity of the semiconductor and the interfacial insulator, respectively. $\mathrm{W}_{\mathrm{D}}$ is the weight of depletion layer obtained from $1 / \mathrm{C}^{2}-\mathrm{V}$ plots at $1 \mathrm{MHz} . \mathrm{I}_{0}$ is the saturation current which obtained from the straight line intercept of the $\ln I-\mathrm{V}$ curves at $\mathrm{V}=0$. The values of interface states as a function for D1, D2 and D3 diodes were calculated by using Eq. (13) and (14).

For p-type semiconductors, the energy of the $E_{s \mathrm{~s}}$ with respect to the top of valence band at the surface of semiconductor is described by the following equation,

$$
E_{S S}-E_{V}=q\left(\phi_{e}-V\right)
$$

The obtained energy dependent distributions of interface states were given in Fig.7.

These values are suitable for a semiconductor as described in the literature. Fig.7 shows that interface states increase the middle of the forbidden energy band gap towards the top of valence band for typically three diodes in the same feature. The $\mathrm{D}_{\mathrm{it}}$ versus Ess-Ev changes from $5 \times 10^{12}$ to $1 \times 10^{11} \mathrm{eV}^{-1} \cdot \mathrm{cm}^{-2}$ for $\mathrm{D} 1,4 \times 10^{12}$ to $1.4 \times 10^{11} \mathrm{eV}^{-1} . \mathrm{cm}^{-2}$ for $\mathrm{D} 2,3 \times 10^{12}$ to $1.2 \times 10^{10} \mathrm{eV}^{-1} . \mathrm{cm}^{-2}$ for D3 diode. 


\section{Conclusion}

The electrical characteristics of the fabricated Al/ALD-grown ZnO/p-Si Schottky barrier diodes have been investigated with help of standard thermionic emission (TE) theory, Norde's function and Cheung method. The I-V characteristics of the diodes were measured under dark and at room temperature. For three diodes, the ideality factor and barrier height values were obtained from standard thermionic emission (TE) method, 1.44 and $0.73 \mathrm{eV}$ for D1 diode, 1.75 and 0.73 for D2 diode and 1.64 and 0.72 for D3 diode, respectively. The barrier height determined from Cheung method was found to be $0.76 \mathrm{eV}$. Moreover, the barrier height obtained from Norde's function that was limited to the highly idealized case of $n=1$ exactly match those of Standard method. In addition, the measured densities of interface states in this study are sufficient level for the performance of the device. As results, the fabricated diode can be used for NIR Schottky photodetector applications.

\section{Acknowledgements}

This work is financially supported by Gazi University BAP office with the research project number 65/2017-01.

\section{References}

1. Özgür Ü.; Aliov Y.I.; Liu C.; Teke A.; Reshchikov M.A; Dogan S.; Avrutin V.; Cho S.J.; Morkoç H.; J. Appl. Phys. 2005, 98, 041301.

2. Klingshim C.; Phys. Status Solidi (b) 2007, 244, 9, 3027-3073.

3. Pearton S.J.; Norton D.P.; Ip K.; Heo Y. W.; Steiner T.; Superlattices Microstruct. 2003, 34, 3-32.

4. Reynolds D.C.; Look D.C.; Jogai B.; Solid State Commun. 1996, 99, 873-875.

5. Wracback M.; Shen H.; Liang S.; Gorla C.R.; Lu Y.; Appl. Phys. Lett. 1999, 74, 507.

6. Szarko J.M.; Song J.K.; Blackledge C.W.; Swart I.; Leone S.R.; Li S. and Zhao Y.; Chemical Physics Lett. 2005, 404, 171-176.

7. Ye J.D; Gu S.L; Zhu S.M.; Liu W.; Liu S.M.; Zhang R.; Shi Y.; and Zheng Y.D.; Appl. Phys. Lett. 2006, 88, 182112. 
8. Hui S.; Zhang Q.-F.; and J.-L. Wiu; Nanotechnology, 2006, 17, 9, 2271.

9. Chen S.; Zhang J.; Feng X.; Wang X.; Luo 1.; Shi Y.; Xue Q.; Wang C.; Zhu J. and Zhu Z.; Applied Surface Science 2005, 241, 384-391.

10. Al Asmar R.; Atanas J.P.; Ajaka M.; Zaatar Y.; Ferblantier G.; Sauvajol J.L.; Jabbour J.; Juillaget S. and Foucaran A.; Journal of Crystal Growth, 2005, 279, 394-402.

11. Barnes T.M.; Leaf J.; Hand S.; Fry C. and Wolden C.A.; Journal of Crystal Growth, 2004, 274, 412-417.

12. Chaabouni F.; Abaab M. and Rezig B., Superlattices and Microstructures, 2006, 39, 171-178.

13. Abou Chaaya A.; Viter R.; Bechelany M.; et al.; Beilstein J. Nanotech. 2013, 4, 690-698.

14. Leskela M. and Ritala M.; Thin Solid Films, 2002, Vol. 409,138-146.

15. Pinna N.; Knez M.; Atomic Layer Deposition of Nanostructured Materials, WILEY, 2012, 41-51.

16. Hwang C. S.; Yoo C.Y.; ' Atomic layer deposition of noble metal thin films', Ph. D. dissertation, University of Helsinki)

17. T. Aaltonen; Atomic layer deposition of noble metal thin films, Ph.D. dissertation, University of Helsinki, 2005.

18. Leskela M. and Ritala M.; 2003, Atomic layer deposition chemistry: recent developments and future challenges, Angew. Chem. Int. Ed. Engl. 2003, 42(45), 5548-54

19. Leskela M. and Ritala M.; Atomic layer deposition, Handbook of thin film materials, I Ed.: Nalwa H.S). Academic Press, San Diego, 2002, 1031159.

20. Becker J.S.; Atomic layer deposition of metal oxide and nitride thin films.Ph. D. dissertation, Harvard University 2003.

21. Tynell T. and Karppinen M.; Semiconductor Science and Technology, 2014, 29, 4, 043001, 0268-1242.

22. Wang Z.L; J Phys: Condens Matter. 2004, 16:829-858.

23. Bilge Ocak S.; Selçuk A.B.; Aras G.; Orhan E.; Materials Science in Semiconductor Processing, 2015, 38, 249-256.

24. Wang Z.L; J Phys: Condens Matter. 2004, 16:829-858.

25. Sze S.M.; Physics of Semiconductor Devices, 2nd ed., Wiley, New York, 1981.

26. Norde H; J. Appl. Phys. Lett. 1986, 49, 85.

27. Cheung and S.K. and Cheung N.W.; Appl.Phys. 1986, 49, 85.

28. Güllü O.; Aydoğan S.; Türüt A.; Microelectron, Eng. 2008, 85, 1647-1651.

29. Card H.C.; Rhoderick E.H.; J Phys D:Appl. 1971; 4, 1589-601.

30. Rhoderick and E.H. and Williams R.H.; Metal-Semiconductor Contacts, Oxford Press, 2nd ed. Clarendon, 1988. 


\section{FIGURE CAPTIONS}

Figure 1. Schematic representational cross-sectional views of $\mathrm{Al} / A L D$-grown $\mathrm{ZnO} / \mathrm{p}-\mathrm{Si}$ Schottky diode.

Figure 2. (a) 2D (b), (c) 3D of the AFM surface morphology of $\mathrm{Al} / A L D$-grown $\mathrm{ZnO} / \mathrm{n}-\mathrm{Si}$ Schottky diode on the $3 \times 3 \mu \mathrm{m}^{2}$ scan area.

Figure 3. SIMS depth profile of the $\mathrm{ZnO}$ film on p-type $\mathrm{Si}$.

Figure 4. Semi-logarithmic I-V characteristics of the Al/ ALD-grown ZnO/p-Si Schottky diodes.

Figure 5. Norde plot of $\mathrm{F}(\mathrm{V}, \mathrm{I})$ for $\mathrm{Al} /$ ALD-grown $\mathrm{ZnO} / \mathrm{p}$-Si diodes.

Figure 6. The $\mathrm{dV} / \mathrm{d}(\mathrm{ln} \mathrm{I})$ vs. I and $\mathrm{H}(\mathrm{I})$ vs I characteristics of $\mathrm{Al} / A L D$-grown $\mathrm{ZnO} / \mathrm{p}$-Si diodes.

Figure 7. The $\mathrm{D}_{\mathrm{it}} \mathrm{vs}$. Ess-Ev of $\mathrm{Al} / A L D$-grown $\mathrm{ZnO} / \mathrm{p}-\mathrm{Si}$ structure. 


\section{TABLES CAPTIONS}

Table 1. Electrical parameters from calculated I-V measurements of $\mathrm{Al} /$ ALD-grown $\mathrm{ZnO} / \mathrm{p}-\mathrm{Si}$ diodes. 


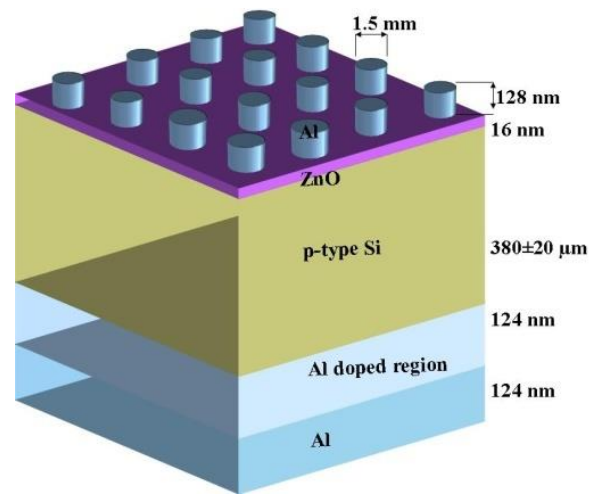

Figure 1 


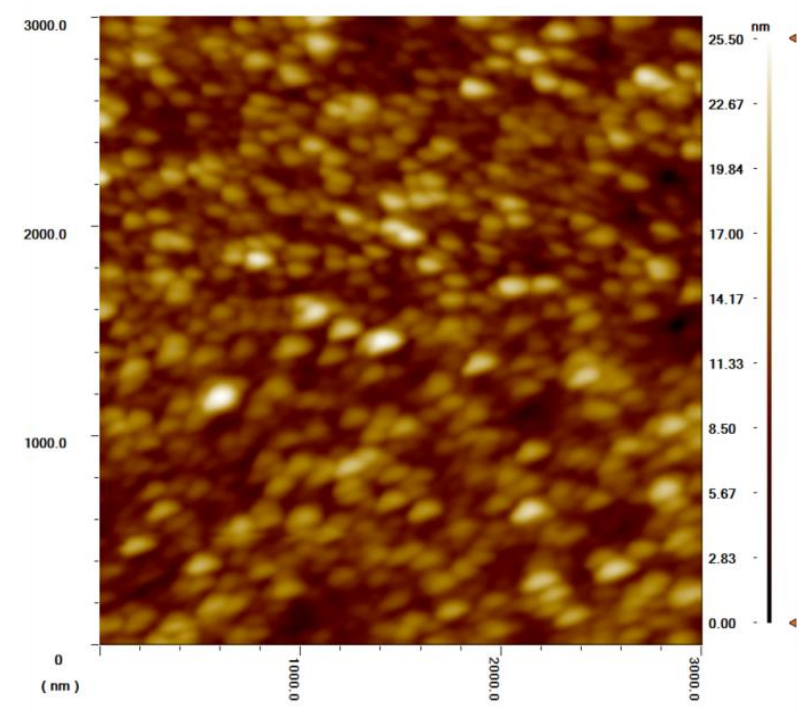

a)

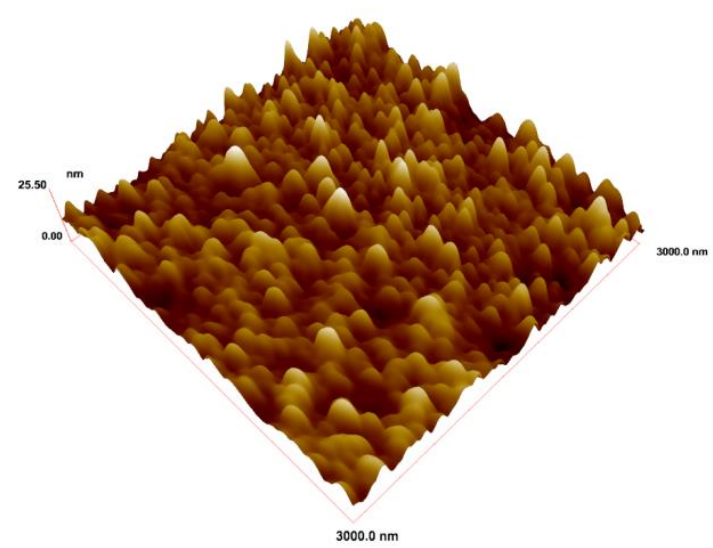

b)

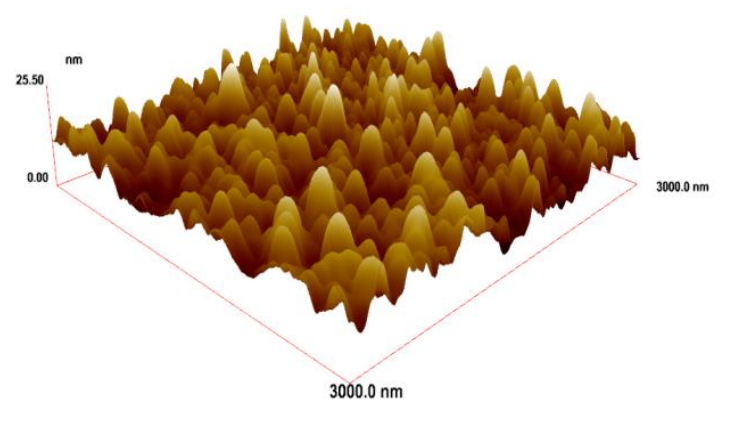

c)

Figure 2 


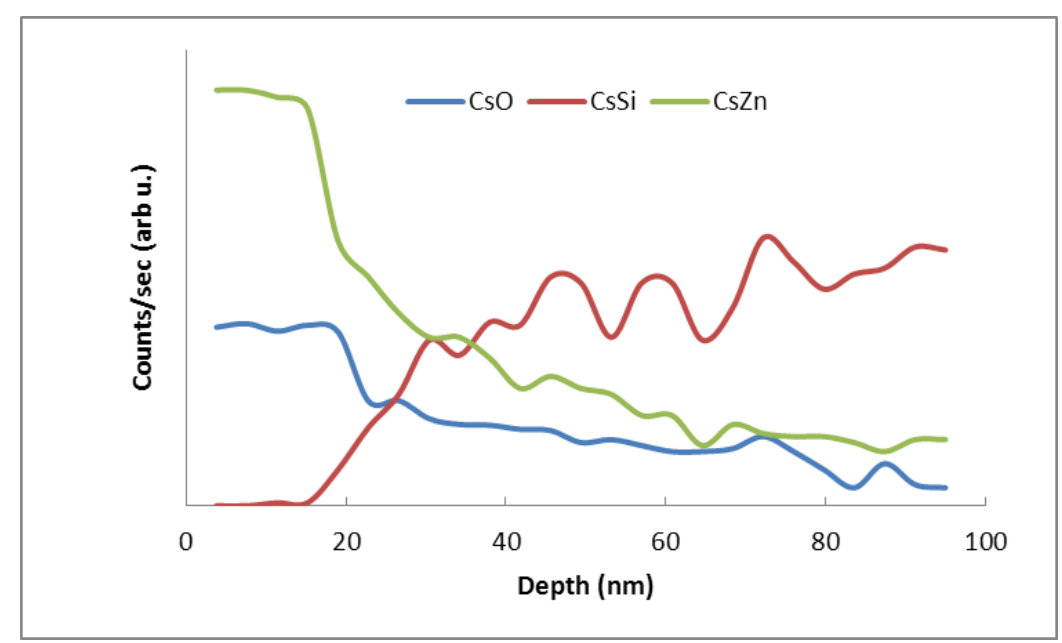

Figure 3 


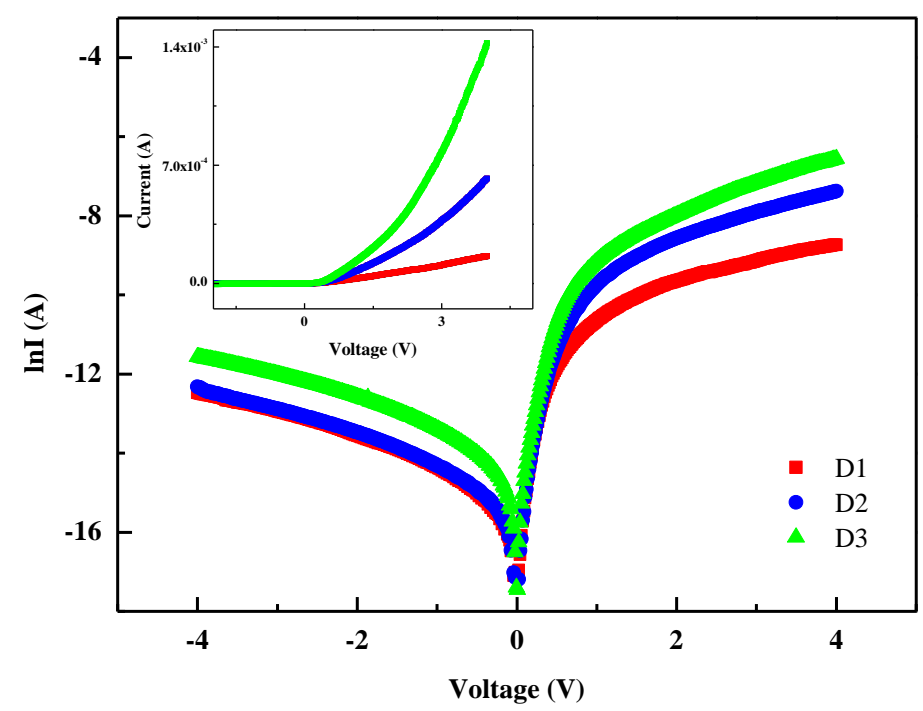

Figure 4 


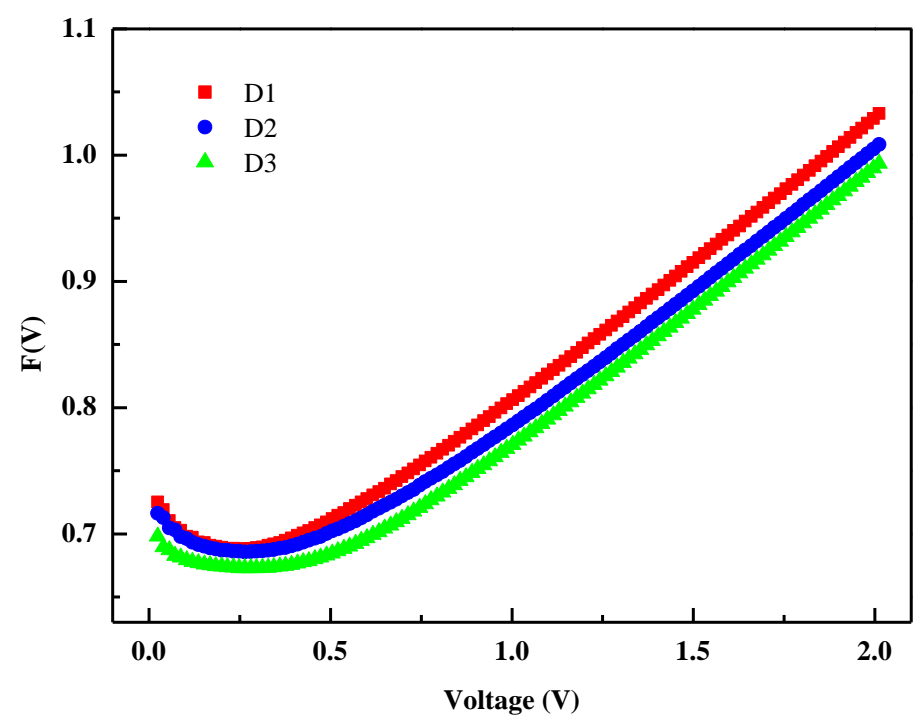

Figure 5 


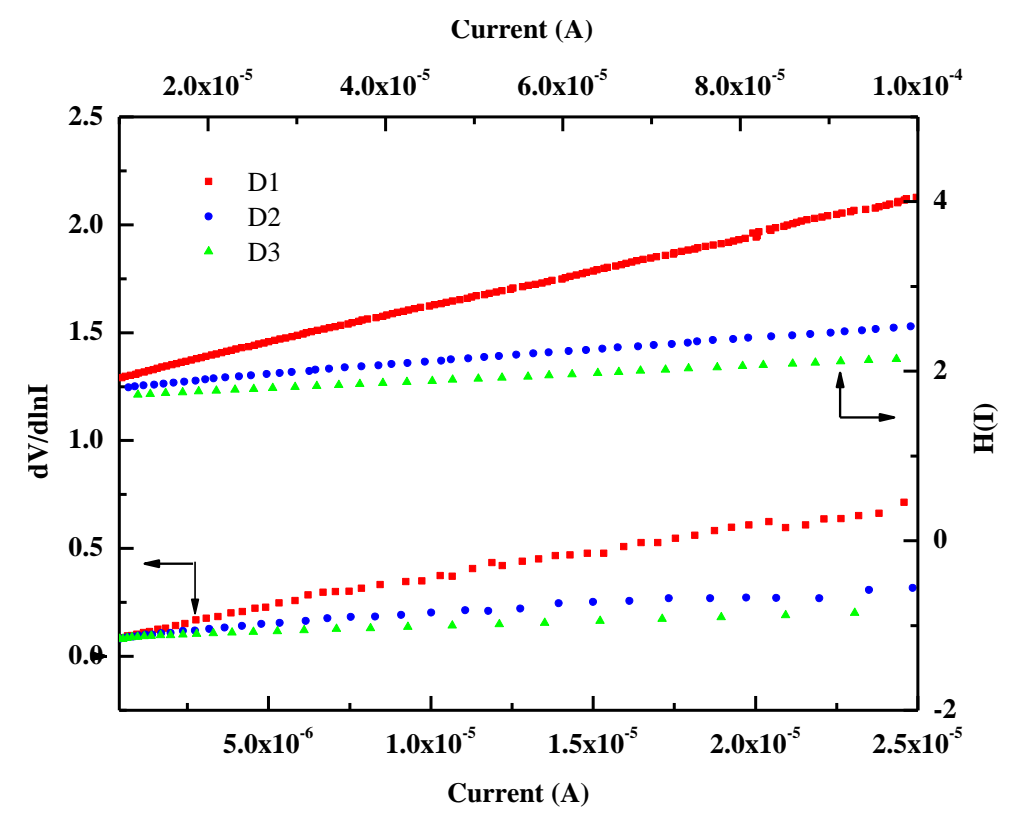

Figure 6 


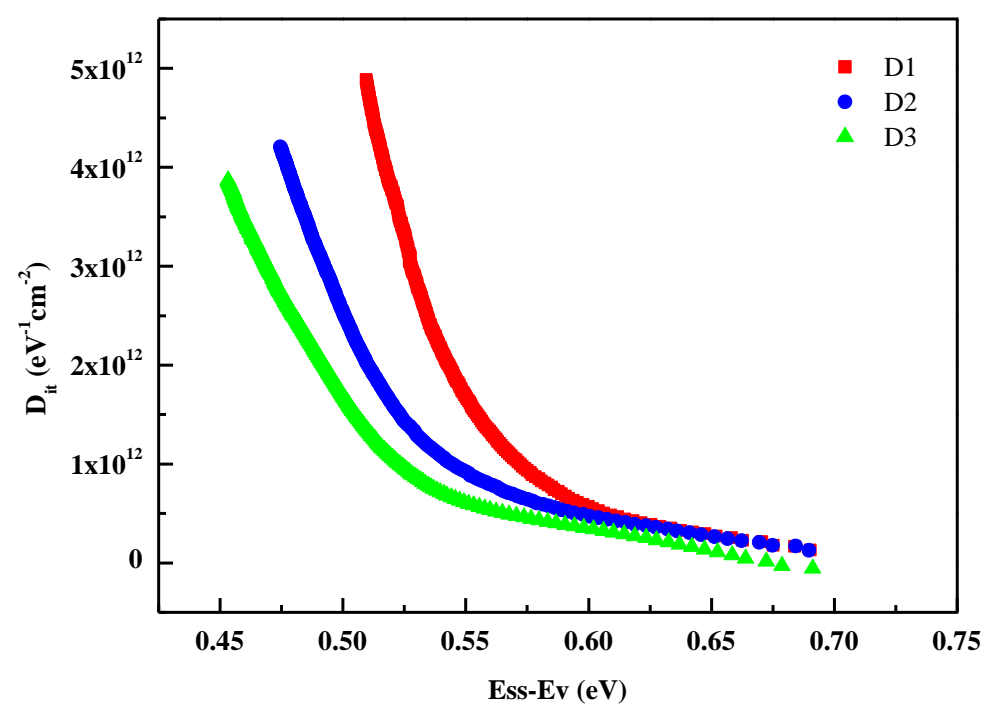

Figure 7 
Table 1

\begin{tabular}{|c|c|c|c|c|c|c|c|c|c|c|}
\hline \multirow{3}{*}{\multicolumn{2}{|c|}{ Methods }} & \multicolumn{9}{|c|}{ Diodes } \\
\hline & & \multicolumn{3}{|c|}{ D1 } & \multicolumn{3}{|c|}{ D2 } & \multicolumn{3}{|c|}{ D3 } \\
\hline & & $\mathbf{n}$ & $\begin{array}{c}\boldsymbol{\Phi}_{\mathrm{b}} \\
(\mathbf{e V})\end{array}$ & $\begin{array}{c}\mathbf{R}_{\mathrm{s}} \\
(\mathbf{k} \boldsymbol{\Omega})\end{array}$ & $\mathbf{n}$ & $\begin{array}{c}\boldsymbol{\Phi}_{\mathbf{b}} \\
(\mathbf{e V})\end{array}$ & $\begin{array}{c}\mathbf{R}_{\mathrm{s}} \\
(\mathrm{k} \boldsymbol{\Omega})\end{array}$ & $\mathbf{n}$ & $\begin{array}{c}\boldsymbol{\Phi}_{\mathrm{b}} \\
(\mathrm{eV})\end{array}$ & $\begin{array}{c}\mathbf{R}_{\mathrm{s}} \\
(\mathrm{k} \Omega)\end{array}$ \\
\hline \multicolumn{2}{|c|}{ Standard } & 1.44 & 0.73 & - & 1.75 & 0.73 & - & 1.64 & 0.72 & - \\
\hline \multicolumn{2}{|c|}{ Norde } & - & 0.73 & 174 & - & 0.73 & 170 & - & 0.71 & 111 \\
\hline \multirow{2}{*}{ Cheung } & dV/dlnI vs I & 2.85 & - & 32.93 & 2.54 & - & 34.80 & 2.58 & - & 5.58 \\
\hline & H(I) vs I & - & 0.72 & 21.56 & - & 0.81 & 7.01 & - & 0.77 & 4.5 \\
\hline
\end{tabular}

